\title{
From service factory to service theatre: Solving the positioning dilemma in the medical practice
}

Received (in revised form): 17th October, 2006

\section{Jean-Paul Berthon}

is a PhD Candidate at the Lulea University of Technology, Sweden. He is also on the faculty in the School of Business at Richmond University, London, where he teaches marketing and has published in journals such as Business Horizons, Journal of International Marketing and The International Journal of Advertising.

\section{Melani Prinsloo}

is a PhD Candidate at the Lulea University of Technology, Sweden. She is a director of Gluemetric, a marketing research company in Pretoria, South Africa, and she also teaches marketing as an adjunct member of faculty at Ecole Nationale Ponts et Chaussees, Paris, France. Her work has appeared in journals such as Advertising Express and International Journal of Technology Marketing.

\section{Leyland Pitt}

is Professor of Marketing at the Segal Graduate School of Business, Simon Fraser University, Vancouver, Canada. His work has been published in The Journal of Advertising Research, The Journal of Advertising, Information Systems Research, Journal of the Academy of Marketing Science, Sloan Management Review, Business Horizons, California Management Review, Communications of the ACM and MIS Quarterly (which he also served as Associate Editor), and in 2000 he was the recipient of the Tamer Cavusgil Award of the American Marketing Association for the best article in the Journal of International Marketing.

\section{Keywords doctor's surgery, operations management, service factory, services} marketing, service theatre

Abstract Doctor's surgeries are typically inefficient: They are generally stuck in the middle of the market, neither providing an individually tailored personal experience, nor one that is fast, efficient and cost effective. Introducing ideas from service simultaneity, and dramaturgy (the theory and practice of dramatic composition), this paper provides a simple but powerful model for the conceptualisation and redesign of the doctor's surgery. We argue that doctor's surgeries that are successful will be those that focus either on standardisation of activities in a back office environment (Service Factory), or high customisation of activities in a front office environment (Service Theatre). Those that attempt to do everything will succeed in doing nothing well.

Journal of Medical Marketing (2007) 7, 55-63. doi:10.1057/palgrave.jmm.5050070

Leyland Pitt Segal Graduate School of Business

Simon Fraser University 515 West Hastings St Vancouver BC, V6B 5K3 Canada

Tel: + 16042687712

Fax: + 16042915122

e-mail: Ipitt@sfu.ca

\section{STUCK IN THE MIDDLE}

Gordon Ramsey in London or Heston Blumenthal's 'Fat Duck' (where such dishes as egg and bacon ice cream or snail porridge are served) command the attention of the world's top restaurant critics. In financial services and consulting, observers are astonished at the sheer efficiency of tax preparation shop H\&R
Block, and are in awe of management consulting firm McKinseys as it crafts strategy for the world's major companies. In the hotel business, it is the French do-it-yourself chain Formule 1, with its no-reception, no-porter, no-bar, norestaurant (in fact, no human contact) business model that is written about. And it is the truly great hotels of the world, 
such as Dubai's Burj-Al-Arab, with its billowing sail design; where guests can choose from 13 different types of pillow, go shopping by chauffer-driven Rolls Royce, or play tennis on the highest tennis court in the world, that make the wish lists of jet set travellers. Institutions in the middle just do not make it. They do not get attention - the ordinary restaurants that do not serve fast food but who would not win Michelin stars either, the legions of large and small consulting firms, and the hotels of the world that range from truly dreadful to pretty good. There is good reason for this.

Organisations in the middle are generally in trouble. Marketing experts might argue that this is because they are "poorly positioned ${ }^{1}$ but this is an oversimplification. In many cases, the problem would not be fixed by clever advertising or promotions, or anything as straightforward as a paint job for the building or new uniforms for the staff. The admired organisations at the end of their spectrums apply more than simple positioning as something 'done to the mind of the customer'. They do much more to the processes that they use to deliver want satisfaction to the market, and are especially adept at streamlining processes in ways that deliver value to customers. This is regardless of whether the customer is hungry and on a budget or wants to celebrate a special occasion; whether they simply need a bed for a night or want to spend the night of their lives. These simple processes can be identified and applied in any organisation that delivers service. They certainly apply in a medical doctor's practice.

In this paper, we show how some simple principles from operations management, services marketing and the theatre can be applied to the medical practice in order to position it at one or the other end of a spectrum. We begin by noting two seemingly disparate observations from sociology on the one hand and the services marketing literature on the other. These observations then permit the construction of a simple matrix that facilitates a classification of the everyday activities that occur in every medical practice. We then show how these activities can be compressed in a way that allows one of two practice models to emerge - very different, but very viable models. We also show why it is typically those practices that are still stuck in the middle that will be less successful. Our conclusion speculates on what this type of thinking will hold for the future of doctor's surgeries, raises some caveats and suggests next steps to follow.

\section{STAGES}

The sociologist Erving Goffman ${ }^{2}$ argued in the 1950s that as individuals we are torn between the desire to act spontaneously and the need to follow social expectations. Individual attempts to follow social expectations are best understood as dramatic, or theatrical, performances (what has subsequently been referred to as dramaturgy). In these performances, individuals endeavour to persuade others that they are indeed consistent and stable people who play their social roles well. Extending the dramaturgical metaphor further, Goffman reasons that the social world is composed of front stages, back stages and regions outside of either the front or back stage (often termed 'offstage'). The front stage is the social region where fixed and socially recognisable performances unfold. The back stage includes spaces where performers are not observed by their audience and, as such, performers can reveal facts and engage in actions that might otherwise undermine the integrity of a front-stage performance. An example in a medical practice might be: The patient experiences the doctor taking 
blood, or listen to their heart through a stethoscope (front stage); the doctor in the back room waiting for an X-ray, but scratching their nose while they do so (back stage), and so unobserved by the patient, who might be a little put off if they did see); the patient encounters the doctor in the supermarket on the weekend (offstage).

The dramaturgical perspective has gained much attention in the management literature $^{3-6}$ and in the services marketing literature in particular. $^{7-9}$ Both researchers and practitioners alike are concerned by the fact that employees in service settings play in a very real sense as performers in a drama, and that many dimensions of this interaction can impact on the level of service the customer receives and the satisfaction they express. Hochschild ${ }^{10}$ suggested the term 'emotional labour' to describe how employees in a service setting perform when they are required to 'feel', or at least project the appearance of feeling, particular emotions as they engage in job-related interactions. Practitioners in a surgery setting may feel and show sympathy for a patient's discomfort, but are indeed expected to demonstrate that they feel and show sympathy (and expect it of themselves). This emotional labour can produce stress in the individual who is expected to perform it (especially where the feelings are not necessarily genuine, and are only 'acted').

From an organisational perspective, it is probably simpler to reduce the notions of front stage and back stage to what may be termed 'front office' and 'back office' as these terminologies are commonly used in the everyday language of many organisations (eg 'From Back Office to Front Office'). ${ }^{11}$ Front office activities may be defined as those activities in an organisation that happen in front of the customer, the customer sees and is aware of their occurrence. So, for example, in a restaurant, customers may see servers taking orders, a maître d' welcoming guests, diners receiving their food and so forth. Back office activities are activities that have to occur in an organisation if customers are to receive service, but they do not happen in front of the customer and are not seen by them when they are performed. In the restaurant example, again, the customer does not see dishes being washed, salads being prepared, cleaning taking place, supplies being ordered or the chef grilling a steak. The importance of the front office-back office dichotomy to the design of the medical practice will be addressed shortly.

\section{SERVICE SIMULTANEITY AND CUSTOMISATION}

It has been noted that services differ from physical goods in that they possess certain characteristics that physical goods do not. ${ }^{12}$ Services are intangible, generally heterogeneous (their quality varies depending on who produces them), they are perishable (the minute the capacity to produce them is not used, it perishes) and they are simultaneously produced and consumed. ${ }^{13}$ Whereas the first three characteristics of services generally create problems for services marketers that goods vendors do not experience, simultaneity gives rise to enormous opportunities. For a service to be produced and consumed, it means that both parties to the performance need to be present. The doctor has to be there to do the work, and the patient has to be there to have the work done. The single greatest opportunity created by service simultaneity is customisation.

To customise is to provide, make or alter to individual or personal specifications. This is much easier to do for service providers than it is for goods producers, because the customisation can be done in real time, and in consultation with the customer. For example, a 
hairdresser can ask the customer whether they like the style, whether they want a bit more hair cut off or whether they want it a bit longer on the sides. On the other hand for most goods, customisation implies long waits and high costs.

Just because service producers can customise does not mean they have to. Customisation in service firms needs to be managed, and decisions have to be taken on whether to customise or not. So for example, in its business class section an airline may attempt to customise the service by greeting passengers by name, and offering them a choice of meals and beverages, while in the economy class compartment, passengers will not receive any particular attention at all. In summary, any services producer will be confronted with choices about which aspects of its offering to customise and which not to: there will be activities of high customisation and activities where customisation is low or nonexistent. The implications for the medical practice will be addressed shortly.

\section{FRONT OFFICE, BACK OFFICE AND SERVICE CUSTOMISATION}

In the service operations management literature, Schmenner ${ }^{14}$ uses two dimensions to create a matrix that can be used to classify service firms and their activities. The first dimension is that of labour intensity - the ratio of labour cost incurred to the value of the plant and equipment. Thus, a doctor's practice would be a labour-intensive business, while a trucking firm would not be. The second dimension is the spectrum of customisation, which of course can range from high (every customer has the service customised to their requirements) to low (everyone gets the same). He then argues that successful service firms tend to move toward a diagonal and that the answer is either to be a low customiser in the case of low labour intensity firms or a high customiser where labour intensity is high. Southwest Airlines is a good example of a low labour intensity-low customisation operation, and a top management consulting firm such as McKinsey's would be a good example of a high labour intensity-high customisation operation.

We advance Schmenner's ${ }^{14}$ model. We argue that replacing the labour intensity dimension with the notions of front- and back office, and maintaining the spectrum of customisation enables the construction of a matrix that gives even greater insights into the conceptualisation of service firms. We use this matrix in the case of medical practice to mentally visualise what models of medical practice emerge when we follow Schmenner's advice and move toward the diagonal. The simple matrix constructed from the two dimensions of front and back office, and customisation is illustrated in Figure 1. We have also identified some of the typical activities in a typical medical practice that might resort under the four quadrants in the matrix. These are not exhaustive, but serve merely as illustration.

The next important question to ask is: In which of the quadrants do most everyday problems occur in an archetypal medical practice? The answer, quite simply, is in the low-customised, front office. Long waits at reception, long waits for appointments, unexciting boring waiting rooms and wrong accounts are some of the typical problems that occur here. The low-customised back office is seldom a problem because most of the activities are routine, and in any case, patients do not see (and probably do not want to see) them occurring. The highly customised front office seldom presents mundane everyday problems because here the patient is face-to-face with the health professional. This is not saying it might not present problems, but these will not be of 


\section{Office}

Back

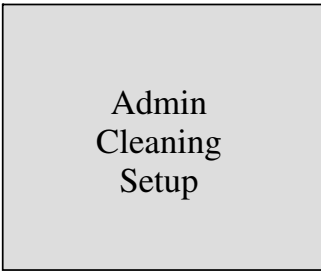

Customisation

High
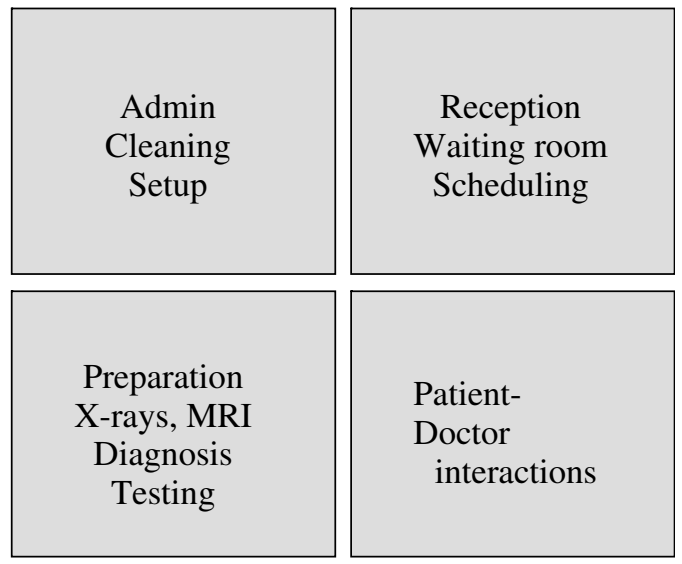

Figure 1: The Front-Back Office - Service Customisation Matrix Applied to a Medical Practice

the everyday, mundane variety, and can generally be dealt with in an individual manner.

The highly customised back office is an enigma, because it is a region of high skill, which the patient does not get to see.

Indeed, the patient might have a lot more respect for a medical practice if they knew just what levels of skill and expertise were operating here. In this way, doctor's surgeries are like most other service firms: The customer often does not get to see the real skill at work, because it is performed in the back office. The highly skilled chef preparing an individualised dish for a diner, and the airline pilot in the cockpit, are just two other simple examples of situations where the real skills of an organisation are invisible to its customers.

Schmenner's ${ }^{14}$ advice is to move toward the diagonal and this is illustrated simply in Figure 2. Figure 2 is a straightforward modification of Figure 1. First, it shows that activities in the low-customisation front office quadrant (where the problems occur) are disposed of by moving them either into the low-customisation back office quadrant, or by shifting them to the high-customisation front office area.
Secondly, it shows that the dilemma of the high-customised back office quadrant ('the magic that nobody sees') is solved by moving the activities either up (to the low-customised back office), or across to being high-customised front office. At this stage, the questions of course are: How could this be done in a medical practice, and secondly, what would the different practice models be like in which these movements occurred?

What might a doctor's practice be like where all low-customised front office activities were moved to the back? There might be no reception, and no waiting room, and no scheduling of appointments. This may be a 'job shop' walk-in type of practice, operating on a first come-first served basis. There would be no large waiting room because this would essentially be viewed as a waste of valuable space for what is really a nonproductive activity. Patients might be checked in, and then given a pager device that would enable them to continue their shopping in a mall or surrounding retail areas to be beeped when their appointment came up. Because as we will see in the next step, the practice will not perform any specialised procedures, accounts and 
Office

Back

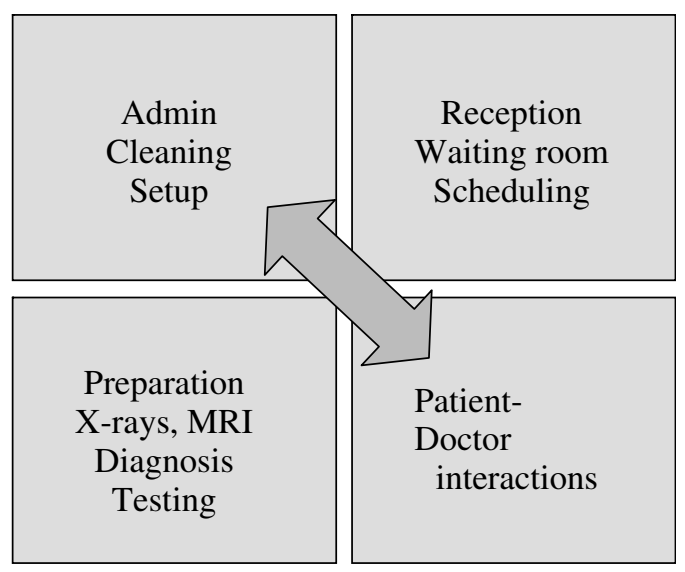

Figure 2: Moving toward the diagonal

payments will be very simple — some kind of 'menu pricing' policy could be implemented, and patients could be requested to pay 'upfront', before receiving services, which will simplify matters greatly. This no-frills practice in strategic terms would be following a cost leadership stance. Employee expenses would be much lower than the average medical practice. The total costs of this practice including costs of construction, equipment and computerisation would all be greatly reduced as well, for these would all be standardised as much as possible.

What will a medical practice be like where all high-customised back office activities become low customised? This type of practice will only concentrate on a small number of particular, probably simple, routine procedures, and will refer any serious problems to specialists. This will also facilitate the simple billing procedures referred to above. We would refer to the model of practice described in the preceding two paragraphs as a 'service factory', and this will be described in more detail later.

Now we examine the type of medical practice that will eventuate when activities are concentrated in the high-customised front office. How will the low-tailored activities be customised? Reception might be very personal, with the patient perhaps even being taken to another room to have details taken down in private. Waiting rooms might be specially appointed with television and internet access, and refreshments might be served. Executives might be given desk space if they require this while waiting. Accounts and billing will be gone through in detail, and explained at the patient's request. Appointments can be made and changed personally, by telephone, or perhaps by means of a website, where the patient can schedule appointments themselves.

Appointments will be confirmed the day before by the practice by way of a medium of the patient's choice - a mailed post card, an email message, a telephone call or an SMS text message to a mobile phone.

When the high-customised back office is moved to the front, the patient gets to see how skilful the medical professional is. Patients can (if they want to) watch technical work being done on implants and prostheses by the medical team. 
Camera images (or video from surgical microscopes) can be captured during the procedures and these can be displayed on operatory monitors. Patients are encouraged to ask questions. Patients get to see X-rays because these are placed on large flat screen monitors for their easy viewing, and these are explained personally. After a consultation, future work can be discussed in detail with the patient by the medical professional in the comfort and privacy of a separate room.

In strategic terms, this type of practice adopts a 'differentiation' stance. This may be either a 'niche'-type practice, such as a premium priced-limited clientele cosmetic plastic surgery practice, or a 'customer focused'-type practice that charges regular fees and provides a broader range of services to a wider customer base. In a 'niche practice', overall costs and especially employee costs may be considerably higher, necessitating higher fees.

We would refer to the type of medical practice that implements the approaches described in the two paragraphs above as a service theatre. Next, we contrast service factories, as illustrated above and service theatres.

\section{SERVICE FACTORIES AND SERVICE THEATRES}

The service factory medical practice model almost has more in common with a mass-production goods producer than with a traditional professional service provider. All the positive language of a factory is appropriate here: mass production, low cost, efficiency, standardisation. And of course some of the negative language as well - impersonal, routine, inflexible. The great benefit of the service factory is that it will deliver consistent, dependable but standardised service at low cost. As such it will not suit all patients, but will appeal most to those who want simple solutions to reasonably simple problems easily, conveniently and affordably. We contend that there is a place in the market for this type of practice.

At the other end of the diagonal spectrum is the medical practice as service theatre, for indeed it has much in common with show business. All the rhetoric of the theatre is appropriate here. Activities do not just happen; they are scripted and staged. Employees are not merely recruited; they are cast, and are in any case performers or actors and not employees. Uniforms become costumes, and equipment becomes props. The practice environment is a set that is carefully and consciously designed to create the mood of the production. Undoubtedly, the offerings of the service theatre will be more expensive, but to the market segment at which they are targeted they will be worth paying for. Patients who patronise this type of practice will do so because it comforts them, really cares for them as individuals, often spoils them and sometimes entertains them. An activity that used to be dreaded may now even be looked forward to as a haven of personal care.

\section{CONCLUSION: PUTTING SERVICE FACTORY-SERVICE THEATRE INTO PRACTICE}

To reiterate a point made at the beginning of this paper, it is service firms at the ends of spectrums that get noticed. It is generally those in the middle that are at worst, in trouble, and at best, struggling to stand out in a competitive and dynamic environment. This is as true of medical practices as it is true for architects, restaurants, hotels, airlines, hospitals and hairdressers. Organisations 'stuck in the middle' find it difficult to compete successfully and indeed to survive, because they end up trying to 'do it all'. In doing so, they find themselves saddled with the costs of trying to provide good service 
levels in a personalised manner, while not succeeding in this endeavour enough to justify premium margins.

It should be noted that being 'stuck in the middle' of a spectrum and being in the middle of our adapted Schmenner diagonal are not the same thing: One is generally difficult, the other need not be. Being stuck in the middle really means trying to do everything in all four of the quadrants of the Front-Back Office Service Customisation matrix. Practices that do this become blobs that flow in all directions and achieve little despite lots of hard work and effort and considerable spending. Successful organisations, while focusing on being either an efficient factory or a great theatre, will nevertheless utilise the thinking implied in the matrix, and shift activities where appropriate in a way that might cause their centre of gravity to move toward the middle of the diagonal.

A doctor's office may find both opportunities in moving some of its operations to a service factory, while finding other occasions to move some of its operations to a service theatre. An example of this in the general medical arena is Shouldice Hospital (www. shouldice.com), an abdominal wall hernia clinic. ${ }^{15,16}$ In many ways, Shouldice is the ultimate service factory. It only performs inguinal hernia repairs in a production line fashion that is completely predictable with regard to time and cost. The work is done by dedicated surgeons, who do nothing else. The hospital anticipates and eliminates possible problems by filtering out all patients who are potentially risky - the elderly, obese, with heart problems, allergies and diabetics, and referring them to specialists. Patients self admit (nowadays online)) and there is little of the so-called care that they might receive in a conventional hospital: Patients prep themselves and walk to operating theatre for surgery and back to their ward - there are no gurneys. There is no bedside meal service, patients are expected to go to the self-service cafeteria and serve themselves.

There are also marvellous aspects of Service Theatre in the Shouldice environment as well. Shouldice is set in luxurious surroundings and has much more of the atmosphere of a fine hotel or a country club than a hospital. In many ways patients become part of the drama by acting as greeters to new patients assuring them that they have nothing to fear and that they will enjoy their stay. Shouldice has an alumni association that holds regular get-togethers and dinners for ex-patients. So in summary, Shouldice embraces aspects of both service factory and service theatre. Those activities that fit into the factory are placed there and flow smoothly, while those aspects of the business that demand theatre are given the prominence that they deserve.

A medical practice can use service factory - service theatre thinking as a tool to reconceptualise and redesign itself, indeed, to reinvent itself. A simple classification of as many activities that occur in the practice as possible can be made using the matrix in Figure 1, for our simple listing is not exhaustive. Then simple 'what if?' questions should be asked of each activity: What would it be like, in the case of low-customised front office activities, if we moved it from right to left, or from top to bottom? The same procedure can be conducted for highcustomised back office activities. A pattern may emerge that sees movement towards one end of the spectrum or the other. The new practice envisaged may be much more like a factory, or much more like a theatre. These are the opportunities.

Our argument is not that medical practices in the 'middle market' cannot survive and produce positive returns, or that they are bad business models. Rather, it is that in order to compete successfully, 
grow and increase revenues they must realise that middle of the road products and services in a wide range industries are being squeezed by premium- and no-frills offerings. There is good recent empirical evidence of this. ${ }^{17}$ We suggest that our framework provides a mechanism for examining opportunities to break out of the 'middle ground'. Of course, the opportunities need to be evaluated in terms of a number of other factors, the most important of which will be the extent to which the proposed new business model will fit with the market the practice intends to serve, and the skills and personal aspirations of the principal or partners. The matrix is after all, just a tool and not a prescription for practice success. Used wisely, however, it has the potential to uncover hitherto undreamed of opportunities in medical practice.

\section{References}

1 Ries, A. \& Trout, J. (1982). Positioning: The Battle for Your Mind, Warner Books, New York, NY.

2 Goffman, E. (1999). The Presentation of Self in Everyday Life, Peter Smith Pub Inc, New York, NY.

3 Clark, T. \& Mangham, I. (2004). From dramaturgy to theatre as technology: the case of corporate theatre. $J$. Manage. Stud. 41(1), 37-59.

4 Haahti, A. (2003). Theory of relationship cultivation: a point of view to design of experience. J. Bus. Manage. 9(3), 303-321.
5 Gardner, W. L. (1992). Lessons in organizational dramaturgy: the art of impression management. Org. Dyn. 21(1), 33-46.

6 Ritti, R. R. \& Silver, J. H. (1986). Early processes of institutionalization: the dramaturgy of exchange in interorganizational relations. Admin. Sci. Q. 31(1), 25-39.

7 Grove, S. J., Fisk, R. P. \& Laforge, M. (2004). Developing the impression management skills of the service worker: an application of Stanislavsky's principles in a services context. Ser. Ind. J. 24(2), 1-14.

8 Grove, S. J., Fisk, R. P. \& John, J. (2003). The future of services marketing: forecasts from ten services experts. J. Ser. Market. 17(2), 107-121.

9 Grove, S. J. \& Fisk, R. P. (1997). The impact of other customers on service experiences: a critical incident examination of 'Getting Along'. J. Retail. 73(1), 63-65.

10 Hochschild, A. (1983). The Managed Heart: Commercialization of Human Feeling, University of California Press, Berkeley, CA.

11 From back office to front office, Available at http: // www.accenture.com $/ x d / x d$.asp? $i t=$ enweb $\& x d=$ industri es $\% 5$ Ccommunications $\% 5$ Caerospace $\% 5$ Cinsights $\% 5 \mathrm{Cb}$ ack_office.xml. Accessed on 23rd March 2005.

12 Berry, L. L. (1980). Services marketing is different. Business, May-June 24-30.

13 Berthon, P. R., Pitt, L. F., Katsikeas, C. \& Berthon, J. -P. (1999). Virtual services go international: international services in the marketspace. J. Int. Market. 7(3), 84-105.

14 Schmenner, R. W. (1986). How can service businesses survive and prosper? Sloan Manage. Rev. 3, 21-32.

15 Bendavid, R. E. E. (1995). Shouldice: a biography. Prob. Gen. Surg. 12(1), 1-5.

16 Hallowell, R. \& Heskett, J. (2004). Shouldice Hospital Ltd. (Abridged). Harvard Business School Case Study 9-805-002, Harvard Business School Publishing, Boston, MA.

17 Knudsen, T. R., Randel, A. \& Rugholm, J. (2005). The vanishing middle market. McKinsey Q. 4, 6-8. 